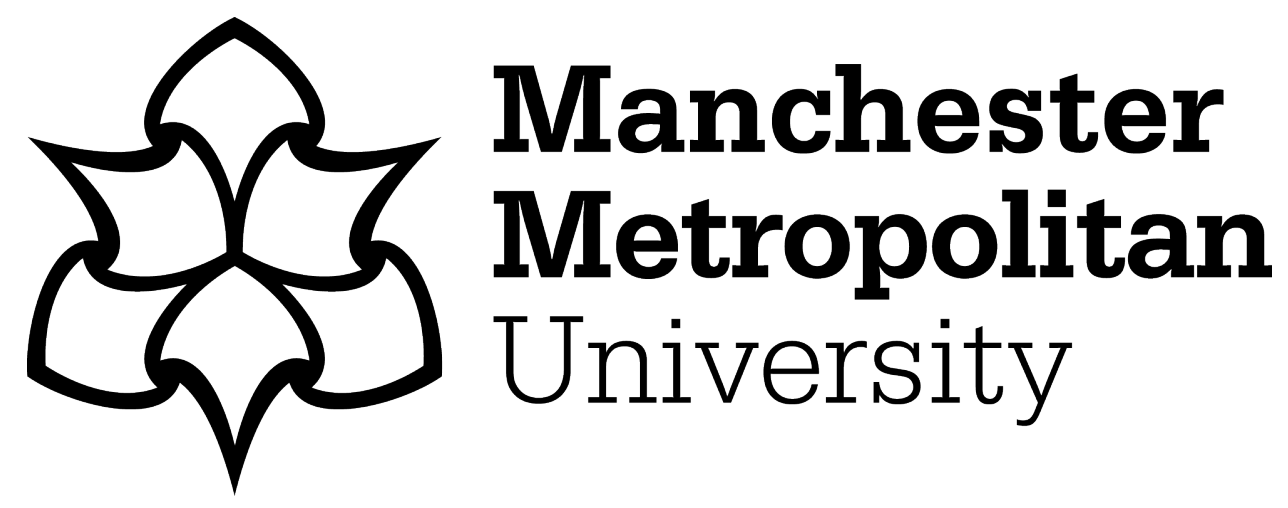

Egan, K (2018) Schrödinger's notes: a minimalist equation for a Reckless Sleepers project. Studies in Theatre and Performance, 39 (2). pp. 177-197. ISSN 1468-2761

Downloaded from: https://e-space.mmu.ac.uk/621790/

Publisher: Taylor \& Francis (Routledge)

DOI: https://doi.org/10.1080/14682761.2018.1519650

Please cite the published version 


\section{Schrödinger's Notes: A Minimalist Equation for a Reckless Sleepers Project}

Kevin Egan

Manchester Metropolitan University

Cheshire Campus

Crewe Green Road

Crewe

Cheshire

CW1 5DU

t: 01612475433

e: k.s.egan@mmu.ac.uk

Twitter:@kevinsegan

ORCiD: http://orcid.org/0000-0002-9404-6733 


\section{$\underline{\text { Abstract }}$}

This article explores the inherent musicality of Reckless Sleepers' theatre work by reflecting on the compositional principles that guide the company's creative process. Focussing on the complex structure of the performance Schrödinger (2011-present), and drawing on the author's involvement as a performer and devisor on the project, the article provides an alternative dramaturgical reading of the processing and organisation of performance material through its relationship to minimalist composition and philosophy. Seeking to identify the score of Schrödinger as a series of musical 'notes', motifs, and melodic phrases that are continually repeated, re-organised, and re-iterated, the author unpacks his own journey through the creation and performance of the work with an emphasis on the structural integrity and signifying potential of the material being 'played'. This article argues that the prioritising of form, style, and tone in the making of Schrödinger are central to an understanding of Reckless Sleepers' practice; one that intentionally places a discussion on meaning at a distance during the creative process and that concentrates on the function of material from a structural, or musical, perspective.

\section{Keywords}

Reckless Sleepers

Schrödinger

Minimalism

Theatre

\section{Musicality}

Composition

\section{Biographical Note}

Kevin Egan is a Senior Lecturer in Contemporary Theatre and Performance at Manchester Metropolitan University. He is also an associate artist with the theatre company Reckless Sleepers, where he has devised and performed in a number of theatre projects, including Schrödinger and Negative Space. As a theatre maker, performer and dramaturg he has also worked with the theatre companies Plane Performance, Pigeon Theatre, Proto-type Theater, and The Strange Names Collective. His research interests are broadly situated within the domain of live art and contemporary theatre, particularly with regard to current trends in theatrical composition. 


\section{Schrödinger's Notes: A Minimalist Equation for a Reckless Sleepers Project}

\section{$\underline{\text { Introduction }}$}

Reckless Sleepers, under the artistic direction of Mole Wetherell, have been making performance projects for over twenty-five years. At present, the company consists of thirteen associate artists from a range of disciplines who are invited to participate in the construction of specific projects, discovering a form that grows out of the expertise and input of those involved. The variety of projects ${ }^{1}$ and artists suggests a preference for working across boundaries and genres, motivated by the theatre, dance, technical, design and visual art backgrounds of its members. Having worked as an associate artist with the company for the past seven years, and as a collaborator, dramaturg, technician and audience member for much longer, I am cognisant of the company's resistance to singular, fixed and prescribed narratives in the work they produce. The devising process is dominated by the building of images, structures and patterns of movement rather than its narrative possibilities, not in an attempt to remove narrative entirely but as a means to keep material open and responsive to other potential readings. The narratives that are produced tend to exist outside of the frame of the performance itself, rarely discussed in detail or shared between the company of performers in the devising process, and often emerging through conversations with audience members after the event. What is important to the company is that these multiple layers and threads can co-exist, producing different ways of understanding the work by not forcing an agenda and by creating an experience that has choice and optionality in how it can be accessed. The company favours an approach that allows an audience to make up their own minds about what it is they are experiencing, reducing the emergence of a singular narrative thread in rehearsals by consciously limiting discussions of what a project might mean from the process. The focus for the company is primarily on the development of an appropriate visual aesthetic and spatial design; on the framing of materials in time and space; on the working out of performance rules and journeys; and on finding opportunities to increase the significance of materials and activities by being economical with the form and content of each performance. Although all of the projects are different in approach and application, these structural and compositional decisions are significant features of a Reckless Sleepers project. The company limits the number of ideas and materials that enter the process, so that those that are used can be examined in more detail; a process of stripping things back to avoid unnecessary clutter and to work through the many possibilities of each idea, object, or material before introducing another. It is from this economical and structural basis that I

\footnotetext{
${ }^{1}$ A list of Reckless Sleepers projects can be accessed on the company website at www.reckless-sleepers.eu/
} 
will begin to analyse one of the company's long-standing projects, Schrödinger ${ }^{2}$ (2011-present), by relating its philosophical and compositional approach to the strategies employed by American minimalist composers of the 1960s and 70s, such as Terry Riley, Steve Reich and Philip Glass. Drawing on key principles of minimalist composition, the article will treat the objects and performers of Schrödinger as a series of 'notes' that are combined, repeated, and arranged within the compositional frame. Identifying a narrative or underlying message as to what the project might represent has rarely taken precedence over discussions on the placement of notes or the development of structural motifs and patterns within its minimalist composition. It is primarily in post-show discussions that we discover how each of us is reading the piece in thematic terms, and it is always fascinating to hear how our individual perspectives are continually changing as we keep on repeating the same performance score. But making sense of this score is the focus; working out the physical relationships between performers, objects, actions and texts. Therefore, an awareness of the musical and minimalist qualities of the project will draw out and reveal more about why, and how, the company responds to performance material in the way that it does.

The performance of Schrödinger takes place within and around a large black box construction complete with doors, hatches, hidden corridors and a roof, where five performers are seen climbing, falling, appearing and disappearing in and out of the box for the duration of the performance. [image 01 here (the box and performers)] They get pushed, dropped, raised and lowered. They manipulate, test and observe one another, recording their findings and predictions on the box in chalk. They break, bend, and reconfigure the rules of the performance, wiping away, drawing over and modifying the chalk markings; experimenting with cause and effect in an attempt to alter the seemingly rigid and repetitive sequences they find themselves in. Interspersed with references to quantum mechanics and Surrealism, this physically demanding performance is concerned with the nature of existence and the construction of our lives, where the inability to define and understand an experience, even in a cyclical process, highlights the fragile, and unstable, position of perception. In quantum mechanics, this can relate to the way electrons, and other quantum-scale objects, behave as particles and waves; they can exist in both of these states up until the moment they are observed or measured. The physicist Erwin Schrödinger, from whom the project takes its name, devised a thought experiment to demonstrate this phenomenon, describing the way a cat enclosed in a box with a flask of poison can be both alive and dead the same time. The implication is that only when the box is opened can the reality of the cat's alive or dead state collapse into a single possibility; closed it maintains the simultaneous existence of both. From a

${ }^{2}$ A version of this performance can be viewed online at https://vimeo.com/38780262 
Surrealist perspective, this translates into the juxtaposition of images, objects and texts, questioning the validity of a singular reading through a celebration of the illogical, irrational and indeterminate qualities of the subconscious. In Schrödinger we refer to a number of artworks by the Belgian Surrealist, René Magritte, which draw attention to the inherent conflict between what is seen, what is implied and what is defined as a consequence of an individual's observation, just as in the thought experiment of Schrödinger's cat. Schrödinger does not explain or describe these ideas and concepts in the performance, but offers an audience the chance to consider how they make sense of the work by showing objects and performers existing in multiple states of possibility. As this project foregrounds simultaneous states of possibility and multiple versions of a potential reality, the emphasis on meaning, from the creators' perspective at least, has to be reduced. The definition and location of what it is about is given less time in the construction, facilitating more connections and relationships between the notes of the performance based on how they are placed and used, not on what meanings they may generate.

What follows then is an attempt to discuss the compositional thinking that takes place in the work, and how this particular project has many of the hallmarks associated with musical minimalism. Thinking about my own position as a performer in Schrödinger, and from my understanding of the company's compositional approach based on my involvement in a range of projects, I will explore how an understanding of what Schrödinger means is enhanced by the performers' attention to a minimalist system of reduction, repetition, the gradual process and its resulting patterns, which are not predicated on a detailed, collective understanding of the meaningmaking process. By removing discussions on meaning and concentrating on the shape, form and experience of the work as it evolves, we escape the need to steer ourselves, or an audience, toward a specific reading of the project. Instead, the work is analysed through the way the 'notes' are played and organised, through how those concrete objects and performers (the notes) are positioned in the ever-evolving performance score so that the readings on offer are multiplied for the observer; who, metaphorically, is invited to open the box and determine which version(s) exist(s).

\section{$\underline{\text { Schrödinger }+ \text { Mathematics }=\text { Musicality }}$}

Successfully negotiating a path through the complex system of activities in Schrödinger requires me and the other four performers in the ensemble to have a firm understanding of the compositional rules that inform, even control, our every move. These compositional rules, and the resulting performance score, are developed through a series of simple mathematical principles that we have discovered, extended and manipulated in the rehearsal process, which continues in the act of performance itself. The focus on patterns of movement, on the dynamics of the performance and its rhythm, on the minute performative details that we might include between fixed points in the score, 
and on our own physical presence in the space provides an alternative dramaturgy of action that finds itself more aligned with the way the materials (including ourselves) fit together from a compositional standpoint rather than on what these compositional decisions might imply for ourselves or an audience. This generates a sense that what we are investigating, in the decisions we make in rehearsals and in performance, is how we can improve the flow of the work itself; what it feels like to perform and where we might need to alter the structure in order to create a better balance between the component parts. Exploring what we can physically do to increase the number of structural relationships and connections across the full range of materials we use. The structure, the score, where we go and what we do, are what drives this process. There is a determination to understand the formal qualities of the composition, to find new ways of 'playing' the score, and to be aware of how each decision made has a consequence and impact on the way it is experienced by both the performers and an audience. Thus, the process of making and performing Schrödinger is characterised by our desire to increase the potential of its composition, overseen by an alternative structural dialogue that, from my perspective, is closely related to the discourse surrounding music composition.

The foundation for Schrödinger was built on an earlier version of the same performance score, devised and performed by a different group of artists in the company between 1998 and 2001. Originally titled Schrödinger's Box, and renamed Schrödinger to distinguish it from the previous incarnation, the project dealt with the famous thought experiment of Schrödinger's cat. Starting with the relationship between truth and lies, the company began to explore a duality of perception through the world of quantum mechanics. Schrödinger is an adaptation of Schrödinger's Box, with a different set of people re-tracing and re-exploring this performance that existed more than fifteen years ago. Therefore, it is no surprise that this re-imagining of the original Schrödinger's Box foregrounded the compositional aspects in the devising process; from the outset we, the performers, were playing with material that had been generated from the original so it might be assumed that the thematic components were already embedded in the activities we were attempting to recreate. But for a project that relies heavily on repetitive sequences, a continual flow of entrances and exits, and on a complicated series of inter-related journeys, it would seem that the necessity to concentrate on the structural integrity of the work has guided the creative process in both Schrödinger's Box and Schrödinger. By his own admission, Artistic Director Mole Wetherell states that 'structures are where I feel most comfortable' (Cited in Brown 2007, 42), and he identifies 'mathematics as an important factor in making work' (Ibid, 18), so there is clearly an interest in patterns here, in seeing how things fit together. In Schrödinger, the relationship to mathematics is displayed through its treatment of numbers, in its use of additive and subtractive sequences, in its adherence to the principle of cause and effect, and its attention to how the 
alteration of one 'note' affects the stability of the composition and necessitates further adjustments. [image 02 here (numbers/maths)] These mathematical and structural concerns that Wetherell employs in the devising process help to create an organised system where the individual 'notes' of Schrödinger can reside, which has similarities with the way composers take the singular, abstract sound of each note and transform them into a musical form.

The comparison between music and theatre composition is explored extensively in the book Composed Theatre: Aesthetics, Processes, Practices (2012) edited by Matthias Rebstock and David Roesner, which focuses attention on the structural, non-narrative, qualities of performance work that is also found in the practice of Reckless Sleepers. In order to examine the compositional thinking that exists in the devising process, Rebstock helpfully connects the two practices with a shared organisational approach that, "permit[s] the translation of basic, static, content-based situations into a regimented temporal framework' (Rebstock 2012, 28). The transformation of these 'basic' building blocks into a complex piece of music, or the dealing with the actual, concrete, physical presence of independent materials through their position in a specific time-frame, allows the musicality of theatre practice to be foregrounded. By attending to the interconnectedness of its component parts rather than on a specific, context-heavy, narrative the composition becomes more concerned with the development of textures and patterns, considering how the notes are placed and played alongside each other rather than on the meaning, they may produce as a result. This musical approach and attitude in the 'working out' of Schrödinger has had a significant impact on the way I understand the project, from the decisions I make in the act of performing to the realisation that I am both the player of notes and a note to be played. I am a performer who is conscious of my place within the score; conscious of my role in adding to or disrupting the harmonic, rhythmic, textural, or dynamic qualities of the work in each moment; acutely aware of the composition as it unfolds through time; and focussed on the musicality, the feeling, of the performance. Of course, there is a difference between being a note in a music composition and a human performer doing something in a theatrical event, as the performer is able to change and interfere with the other notes that they come into contact with in a more complex way than the fixed-frequency notes of a music composition. But what I am interested in here is how the 'doing something' is managed through discussions on how we make these notes interact, and how we can change the same note by considering how it is used, altering it through a variety of methods (for example, like how the same note in music sounds different when played on different instruments, when the amplitude is changed, or if the instrument is bowed, plucked, blown, muted etc.). One might imagine that all of the objects and performers of Schrödinger are fixed notes, with the potential to be played in a variety of ways through their connection and physical relationship to the other notes in the performance. Sometimes the notes do not behave in the way we expect and the notes we present are 
subject to variations and mistakes, like a string breaking on a violin or a misplaced finger on a flute. Even though the composition remains the same, with the same notes being played, they can still surprise and affect the performance, just as a piece of live music can be heard again and again with different nuances and alterations, reminding us that the notes being used are alive and present within the coded composition.

The tightly choreographed score of Schrödinger is reliant on a spatial and temporal awareness of the world the performers inhabit. Connections, observations, and alterations between the material components are made in relation to how they work together within the frame of the entire performance, thus drawing on what David Roesner identifies as an 'exploration of horizontal and vertical connections and relations influenced and inspired by the predominant symbolic notational language of music: the score' (Roesner in Rebstock 2012, 331). Schrödinger, due to its preoccupation with structures, rules, mathematics, spatial and temporal connections, can be aligned with the practice examined in Composed Theatre because it 'takes on some of the qualities of music in that it caters to a perception that is allowed to be less concerned with "what it means" and more with "how it is done"" (ibid, 357). In Schrödinger, this resistance to discussing 'what it is' and our preferred engagement with 'how we do it', demonstrates a desire to think compositionally; to explore the material in the same way a composer might by trying out ideas not for their symbolic or representational effect but for their impact on the performance score itself. This compositional attitude to the development of performance material is widely used by the company and is consciously applied in the rehearsal and performance of many of their projects. Although it is easier to recognise how the making of Schrödinger provided a more focussed examination of the compositional process, as these structures, rules, mathematical and compositional games were inherited from the original Schrödinger's Box, the same principle of resisting meaning and organising materials, texts and images in time and space can be found in the way most of Reckless Sleepers' projects are created.

\section{$\underline{\text { Schrödinger }+ \text { Minimalism }=\text { Structure }+ \text { Process }}$}

If minimalism can be seen as an examination of the temporal and spatial shifts that occur gradually over an extended period of time, then Schrödinger certainly has much to say about this continual, ever-present, notion of process-music synonymous with minimalist composition. Process-music, as the term suggests, exposes a specific compositional process in the act of performing, allowing the evolution of musical material to be determined by the processes it employs. For instance, the composer Steve Reich uses repetitive phrases in his music so that the listener can hear the difference between one iteration and another, making the subtle development of musical phrases the main focus of reception. The organisational and structural decisions of the composer become bound 
up with the process of listening; they are set in motion, and the listener hears the music being made in the moment of performance. Schrödinger's intricate composition, with its predominantly minimalist repetitive structure, is often highlighted as an important feature in the reviews it receives: from Nicola Harrison's comment on the work as 'a mathematical choreographed ensemble of changing, yet repetitive images' (Harrison 2011), Thomas Bacon's assertion that 'it is filled with glorious moments and tedious predictability’ (Bacon 2011), Andrew Westerside's observation that it is 'a work of exquisite skill, precision, compositional and rhythmical craft' (Westerside 2011), to Rod McPhee's criticism that 'it seriously drags' (McPhee 2011). What all of these have in common is that they discuss their viewing experience through the structural aspects of the work and that an understanding of the responses the performance elicits is born out of the reductive, repetitive and minimalist processes it employs. Schrödinger, as the mixed reviews suggest, provides the audience with a form that can be experienced as both simple and complex, whose incessant repetition serves to frustrate and excite the observer in equal measure. Just as minimalism 'demand[s] a new kind of listening' (Schwarz 1996, 9), the performance of Schrödinger also asks for an alternative means of reading and experiencing the work in order to appreciate the function of its reductive, repetitive score; a way of accessing the material that is primarily concerned with how the performers and objects move through a system of ever-changing, yet repetitive, patterns and relationships. This attention to a process of changing relationships in the moment of performance equates to the concept of process-music established through the repetitive phrases in minimalism, where the idea of reaching an end-point or achieving a specific goal are less significant. Due to minimalism's 'general lack of directionality or teleological design' (Mertens 1983, 91), the simple repetitions require the listener to substitute their desire for closure and resolution with an alternative means of describing their experience, because 'neither memory nor anticipation have a place' (Fink 2005, 33). Similarly, Schrödinger refrains from presenting a linear narrative or logical progression of scenes, and there is little to suggest a meaningful purpose to the activities an audience witnesses. There is no definitive story; there is no firm beginning or end to what they are experiencing. The search for meaning is subsumed by the gradual evolution of material, which serves to foreground the instability of observation and perception through its repetitive, cyclical, processes.

Concentrating on the composition itself, on how the performance provides a continual re-evaluation of the material as it repeats, means the audience can focus their attention on how we observe and perceive things in the moment of occurrence and not on what they are observing in relation to their memory of events. The subtle changes that happen as a result of the many permutations of the same notes redirects an audience's attention away from the static nature of repetition being observed (the same thing happens over and over) toward the evolutionary nature of repetition being presented (the same thing keeps changing). Recognising that the repetition is not a product of the performance but 
a process of recalibrating our experience to see how the repetition transforms and recycles the notes; enjoying the journey the repetition takes instead of the result, or destination, of the repetition.

\section{$\underline{\text { Schrödinger }+ \text { Reduction }=\text { Extension }+ \text { Exhaustion }}$}

Minimalist music is based on the notion of reduction, the paring down to a minimum of the materials that a composer will use in any given work.

(Schwarz 1996, 9)

On the surface Schrödinger maintains this reductive attitude that Schwarz refers to. It uses as the basis of the composition a finite number of raw materials to work with (see Fig. 1). These twentyeight 'notes' form the foundation of the performance, allowing the same twenty-eight notes to be reconfigured, manipulated, extended, and layered to create a multitude of patterns and motifs that are repeatable. Just as the composers Steve Reich and Philip Glass 'use the simplest of musical materials, combined and recombined in intricate ways' (Fink 2005, 27), so too does Schrödinger conform to an exploration of its own imposed limitations. That the repeated notes produce various patterns and combinations in order to infer a range of possible readings, and that this process, as in minimalism, 'extend[s] the reduced sound or aural object over time' (Davachi 2012, 24). Reckless Sleepers use a similar tactic of exploring the potential of an isolated idea or object in their process, and, as Wetherell explains, one of the strategies in Schrodinger's Box was to 'pare everything down to its bare bones. Its emotional content. And then to push this (singular idea) further' (Cited in Brown 2007, 24). Although Wetherell assigns the reduction here to its emotional content, I would claim that in Schrödinger this is specifically derived through the performers' response to the system of rules they follow and therefore 'playing' or 'feeling' the notes that have been selected is what generates the emotional content. For instance, the playing of note 1, 'the box', as we climb, fall, enter and exit, get beaten by it, and vandalise it, creates a range of emotional responses for the performers. Yet it is primarily through the physical activity of doing something again and again with this same note that we, the performers, tend to notice these emotional shifts. [image 03 here (Kevin climbing)]

In the initial re-devising stage in 2006, 'Mole suggested that an investigation be made into the letter's journey, its reading, appearance and disappearance' (Brown 2007, 32). Thus, one of Schrödinger's notes (20. Letters) was to be further extended within the performance score: 'what I am interested in now is how much more we can get out of the letter. Where else it fits' (Wetherell in Brown 2007, 35). Again, this persistent re-looking at, and re-assessment of, the singular component parts of the project, and how they are situated within a temporal structure, has an affinity with 'minimalism's deadpan attention to the "pure object"' (Fink 2005, 30) in that it allows a note, or a 
Schrödinger's Notes

\begin{tabular}{|c|c|}
\hline & The Box \\
\hline 4. & $\begin{array}{l}\text { Alex Covell (performer) } \\
\text { Kevin Egan (performer) } \\
\text { Leen Dewilde (performer) } \\
\text { Leentje Van de Cruys (performer) } \\
\text { Mole Wetherell (performer) }\end{array}$ \\
\hline & $\begin{array}{l}\text { Apples } \\
\text { Books } \\
\text { Bookcase } \\
\text { Bottles } \\
\text { Briefcase } \\
\text { Cards } \\
\text { Chairs } \\
\text { Chalk } \\
\text { Glasses } \\
\text { Hammer } \\
\text { Jacket } \\
\text { Ladder } \\
\text { Lamp } \\
\text { Letter } \\
\text { Musical box } \\
\text { Pencils } \\
\text { Pencil sharpener } \\
\text { Sheets } \\
\text { Snow globe } \\
\text { Tables } \\
\text { Water } \\
\text { Watering cans }\end{array}$ \\
\hline
\end{tabular}


simple musical phrase, to be pushed to its limits. Wim Mertens expresses a similar sentiment about the compositions of Terry Riley, whose minimalist music is also used in the performance of Schrödinger: '[He] examines only a small amount of material intensively, and only when the material is exhausted does he add something new to it' $(1983,44)$. This strategy is evident in how an idea or performative motif such as 'mountain', which is significantly featured in Schrödinger, can be explored through the notes themselves. Thus, 'mountain' is identified in my own climbing and falling within the box, with the chalk that draws images of mountains and waves, in the musical box playing Hushabye Mountain, and in Wetherell's repetition of the word as he is carried out of the box etc. [see Fig. 2]. Focussing on how these notes might be played in response to a singular idea, and restricting the number of notes to choose from, means the performers can uncover new combinations, resonances, and ways of playing that may have been left undiscovered if working with a larger selection of materials. Interestingly, these notes extend beyond the sixty-minute performance of Schrödinger as they were taken from the original Schrödinger's Box and have been further explored in two separate devising phases (2006 and 2011). Therefore, the notes themselves have been repeated and developed in each of these incarnations and no new notes have been added, refining and extending the frequency of these twenty-eight notes and discovering alternative combinations and patterns to interrogate. In addition, the cards (note 12) used by Alex Covell in the 'this is a...' section, ${ }^{3}$ where he holds up pencil drawings of archetypal images and 'guesses' what they are whilst covered by a white sheet (note 24), was also extended into a durational performance called A House On A Hill (2002). [image 04 here (Alex holding card)] The company have also explored the mathematical game of 'contacts', a compositional strategy used in a few sections of Schrödinger that dictates the placement of notes, into their latest performance project, Negative Space (2015). In this piece, the game of maintaining a certain number of contact points with the objects (the notes) in the space becomes an integral rule that guides the decision-making process in the moment of performance. The exhaustive potential of these simple materials, signalled by the way the company searches for other performative possibilities, variations on a theme, and alternative patterns with the same notes, is strikingly similar to how Riley's minimalist composition In $C$ (1964) is 'to be conceived more as contributions to an ongoing exploration of its potential than as merely a faithful reproduction of the score' (Potter 2002, 109). With each iteration, with each attempt to play the score we have developed, we notice new things, we explore where the possibilities exist, where the structure can be manipulated, and when these do not 'fit' within the

\footnotetext{
${ }^{3}$ This was also performed by Tim Ingram in the original version and Michael Pinchbeck in the second phase
} of devising/touring). 


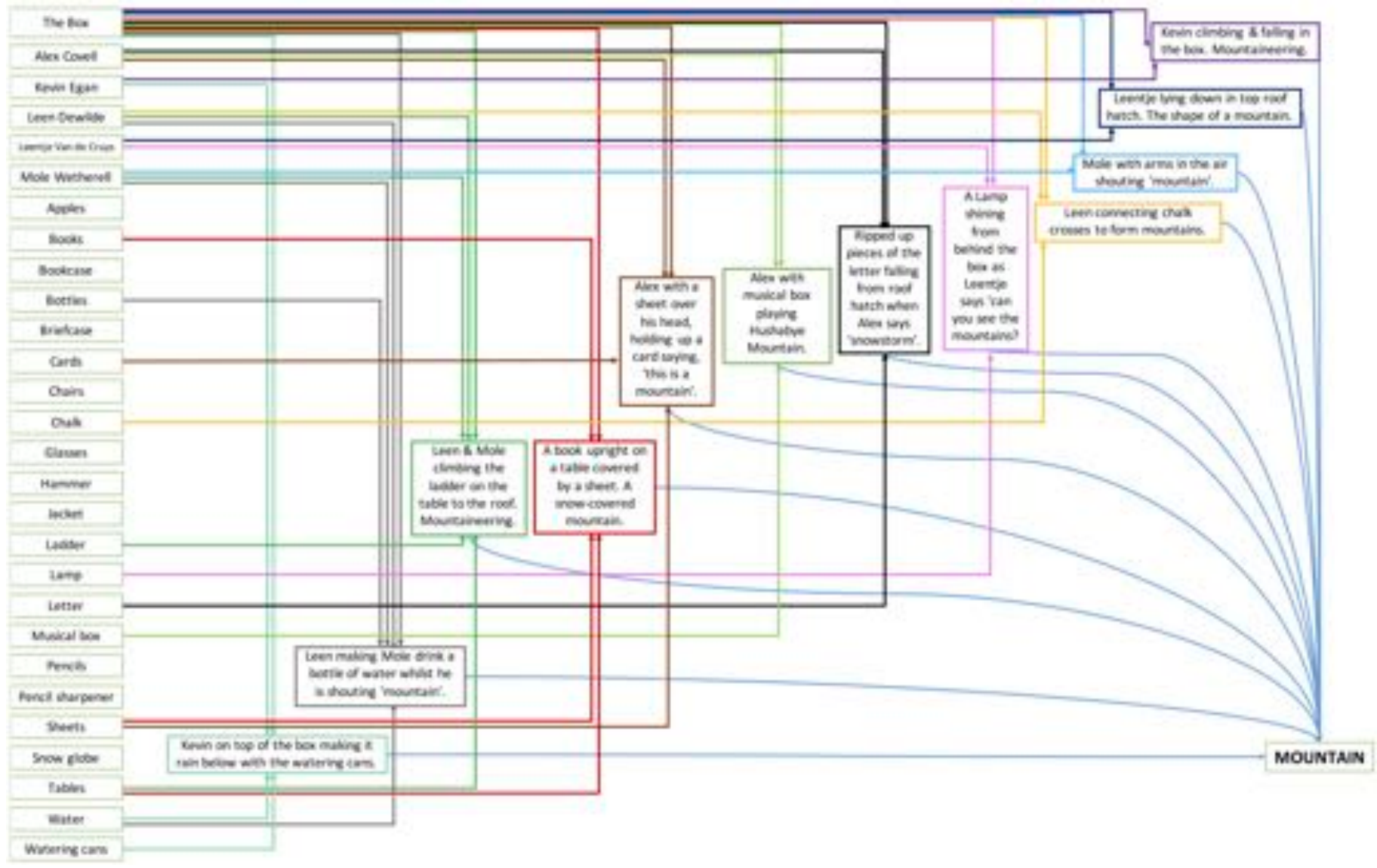


structure of the piece itself there is a need to create another score, another performance, that can house the new composition we discover.

In Schrödinger there is meticulous consideration of the way in which the limited material exists in the overall structure. Some of these notes get used once (9. Bookcase, 21. Musical box, 23. Pencil sharpener) thus breaking the repetitive cycle. Others are used in many ways (In fig. 3 the journey of the letter (note 20) shows how it is read, dropped, followed, concealed in a jacket, passed between performers, and eventually seen as the ripped up pieces of paper that fall from the hatch like a snowstorm) [image 05 here (snowstorm paper)] and others are constant like the box itself. Material is built up from these initial notes and the smaller component parts that make up the performance become the focus for devising further material. Company member, Tim Ingram, explains how this system was used in the re-devising process of Schrödinger: 'various combinations of objects/actions were tried out [...] Image and action juxtaposed and interchangeable until the right combination might occur' (Cited in Brown 2007, 73). A similar method can be found in Reich's minimalist works in that he looks at 'breaking the pattern itself down into individual beats (“interchangeable parts"), and building it up note by note' (Fink 2005, 160), so that these interchangeable, but limited, materials are broken down and re-configured in many ways throughout the compositional process. Deciding what is 'right' or appropriate in the devising process is usually determined by how the combination of notes at a particular moment in time are balanced. Devisors see how these notes relate to each other by testing the new phrase and evaluating whether it moves fluidly through the composition, making sure the change is made as a consequence of something else happening, and not as an isolated moment.

Referring to this minimalist approach, Mertens explains that 'the purpose of the reductionist attitude, then, is in service to an explicitly self-referential end in which focus is directed toward the perception of the thing in itself' $(1983,88)$. With only twenty-eight notes the audience are seeing the same objects over and over again and cannot escape them, yet the continual presence and journey of the same materials draws attention to how they are perceived in different combinations, at different moments (and even in different projects), inevitably leading to a range of potential readings of the thing itself. Thus, the apples (note 7) can refer to the concept of gravity when one falls from the box, as a biblical reference when Leentje Van De Cruys takes a bite from one, as an atom when they are joined together with pencils by Alex Covell, and even as a reference to the green apple seen in a number of Magritte's paintings ${ }^{4}$. [image 06 here (apple)] But at no stage do

\footnotetext{
${ }^{4}$ Reckless Sleepers took their name from an artwork by Surrealist painter, René Magritte. The apple also features in many of their projects.
} 


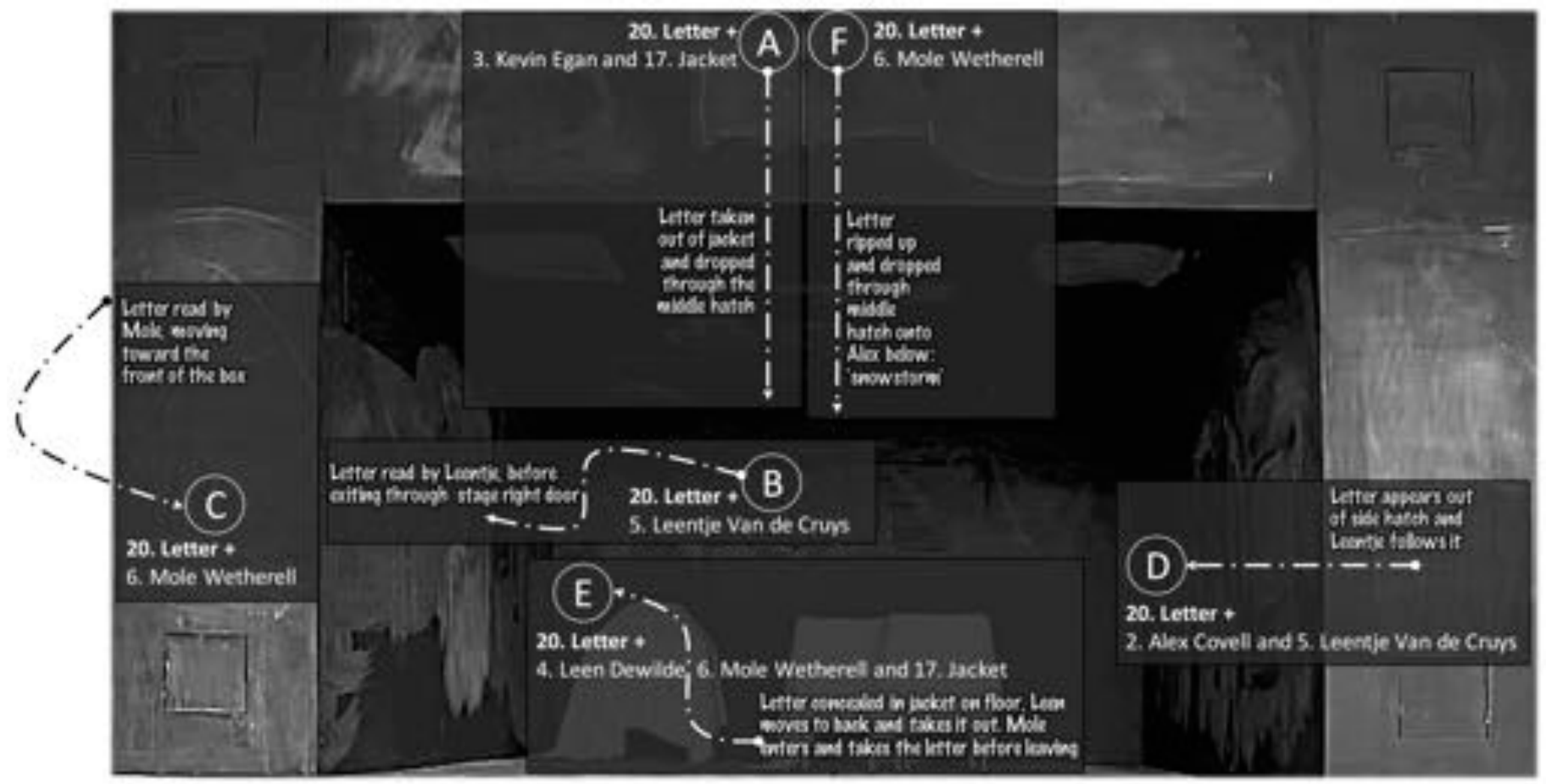


the performers insist on these readings; for us it can still be just an apple, an apple that can enter and exit and be used in a range of different ways. Our focus is on the apple, on the journey it takes moment by moment in the composition, its vertical and horizontal relationships. This reduction opens up the possibilities of the composition, just as the limited number of musical notes can offer an array of styles and genres of music from the same raw materials.

\section{$\underline{\text { Schrödinger }+ \text { Repetition }=\text { Perception }}$}

[Minimalism] not only cuts down the area of sound-activity to an absolute (and absolutist) minimum, but submits the scrupulously selective [...] material to mostly repetitive, highly disciplined procedures.

(Nyman 1999, 139)

We are constantly repeating ourselves in Schrödinger. The same words ('mountain', 'nothing', 'this is a...'), the same motifs (falling through the hatches of the box, the reading and showing of cards, the hammer causing Covell to retreat) [image 07 here (Alex hammer)] and, of course, the same notes occur numerous times. Indeed, the concept of repetition, of doing things 'over and over', is woven into the fabric of the piece as we continue to make sense of these objects and activities that are part of a controlled (although seemingly chaotic) system. Conceptually, the repetition in Schrödinger serves to remind us of the repeated patterns of our everyday lives; the countless rituals we attempt to maintain in order for things to work, to move on, and to 'mean' something to us. The text itself urges the spectator to consider the nature of repetition as it unfolds, drawing attention to the form of the work in the reading of the letter, which appears near the beginning of the performance:

I couldn't help thinking that I had been here before, that somehow my time was being repeated in cycles. In predictable cycles, going over old ground. Travelling in circles.

(Schrödinger 2011)

Thus, these structural principles are foregrounded significantly and the audience are tasked with observing how the form might enable, or deny, a sense of progression (in literal and metaphorical terms). The performance identifies its use of repetition as a means to explore the imperceptible shifts in watching the same thing over and over. Concentrating on how the observer understands the repetition as either progressive or reductive and, fundamentally, places their own reaction to the repetition at the heart of the experience. Steve Reich, through the use of repetition, 'maximises a minimal amount of motivic material' (Fink 2005, 79) and we can equate this with the way in which the twenty-eight notes of Schrödinger are in a similar cycle of repetition. The water (note 27) is used to drink, to clean, to refresh, to rain, and to torture but it is still the same note. [image 08 here 
(water)] In minimalism this is a fundamental compositional strategy; that the incessant repetition serves to foreground subtlety and difference; that its seemingly unchanging surface of repeated notes is an on-going process of intricate alterations that appear to have no beginning or end. These subtle shifts in the ever-repeated patterns can become even more heightened as the spectator listens and watches closely to detect any alteration in the notation. There is a moment in Schrödinger where Alex Covell is handed a snow globe (note 25) after a long period of repeating a sequence of numbers and calling out the names of objects that have already been seen in the performance space. Suddenly another object, another note, is introduced for the first time: the recurring pattern stops for a moment, and then the system of repetition changes. This brief moment is usually received with laughter from the audience because they experience an obvious adjustment to the regular pulse of numbers and objects called out by Covell. It is similar to the way Steve Reich's Phase Patterns functions: 'when, after 15 min or so of a single chord-rhythm, a second, related chord appears, the effect is startling' (Fink 2005, 41). There is a release that occurs in this moment, where the audience finally experience a deviation in the repetitive sequence that they have been waiting, and willing, to happen. Yet, if the spectator looks more closely at the material as it unfolds they will see that beyond the surface of repetition there is a constant stream of fluctuating, shifting, patterns. This minimalist practice, defined as 'a simple process of change involving repeating patterns' (Sadie and Latham 1996, 500), is certainly evident in the way Schrödinger resists the finality of any conclusive position in the material it presents, instead dealing with ideas, images, and patterns in a state of flux through its use of repetitive processes.

\section{Schrödinger + the Gradual Process $=$ Mutation}

The gradual process of change, seen through the regular pulse of re-iterated notes and phrases, 'underlies the complex evolution of musical patterns' (Fink 2005, 20) and is parallel to the way in which the concrete 'notes' being explored in the performance of Schrödinger are continually reordering and re-positioning themselves in response to the repetitive nature of the work. The addition of extra performers and books in the 'Hammer Back Look' section, ${ }^{5}$ or the subtraction of

\footnotetext{
${ }^{5}$ This is the section in Schrödinger where Kevin Egan attempts to reach Alex Covell with a hammer in his hand, whilst maintaining a set number of contacts in the space. When Covell touches the wall, holds a book or a briefcase, the number of contacts increases and Egan has to drop the hammer. The game of 'cat and mouse' is then complicated further when other performers enter and add more contact points to the system.
} 
performers, tables, and chairs in the 'drinking' section, ${ }^{6}$ [image 09 here (drinking)] both rely on this manipulation of the repetitive sequence. Whilst the repetition is evident in the paths the performers follow, or in the same objects and 'notes' that are present in each occurrence, the gradual addition and subtraction of material allows these sequences to evolve and adapt to the very system it attempts to maintain. The performance does repeat, but each repetition has mutated, and it becomes difficult to distinguish where one phrase ends and another begins due to the gradual process of alteration that occurs. In Fig. 4 the gradual process of change between the first and second iteration of the 'Hammer Back Look' section is apparent in the alteration of individual notes within the same pattern of contacts. Therefore, the motif can be viewed as a repetition of the same structural process, and also as a mutation of the melodic pattern because some of the notes are different. In the original motif contacts are made with the hammer (note 16), the books (note 8) and the box (note 1). In an attempt to maintain two contacts (the agreed number of contacts between the two performers playing the game) the book is dropped on the floor. In the repeated motif the touching of the box is replaced by the holding of the briefcase (note 11), and the book is once again dropped, returning the pattern to its normative state of two contacts. The next change between the two iterations occurs when contacts with the box and briefcase are extended, causing the second iteration to delay contacts with the hammer and box. The notes remain the same here, but their configuration in the structure alters the melodic pattern. The third change happens with the introduction of a new 'note' into the game, the tables (note 26), which signals the beginning of a third iteration that still plays with the logic of contacts but transforms into a previously unseen, or unheard, motif. This foregrounding of the changing repetitive sequences allows audiences to notice how the work is 'starting and ending without boundaries' (Locke 2011), and how 'most actions are usually not what they might at first seem' (Hutera 2011). Thus, the experience of watching Schrödinger is highlighting the instability and difficulty of reading repetition as repetition. The purpose of this repetitive structure then is really about difference, whether sudden or gradual, and the audience are being asked to look at the smaller details (on the quantum level if you will) and on how they observe and perceive that repetition: that it depends on how one looks at it (or listens to it). Riley sees the value of repetition as a way of noticing things that would normally be filtered out, suggesting that 'things didn't sound the same when you heard them more than once. And the more

${ }^{6}$ This section begins with four tables and chairs in the space, where Alex Covell calls out numbers that have a specific action attached, which the other performers have to follow (relating to a wine bottle, glass and the drinking of water). This is repeated a number of times and becomes increasingly difficult to maintain as the pace increases and tables and chairs are removed. 
'Hammer Back Look': the gradual process

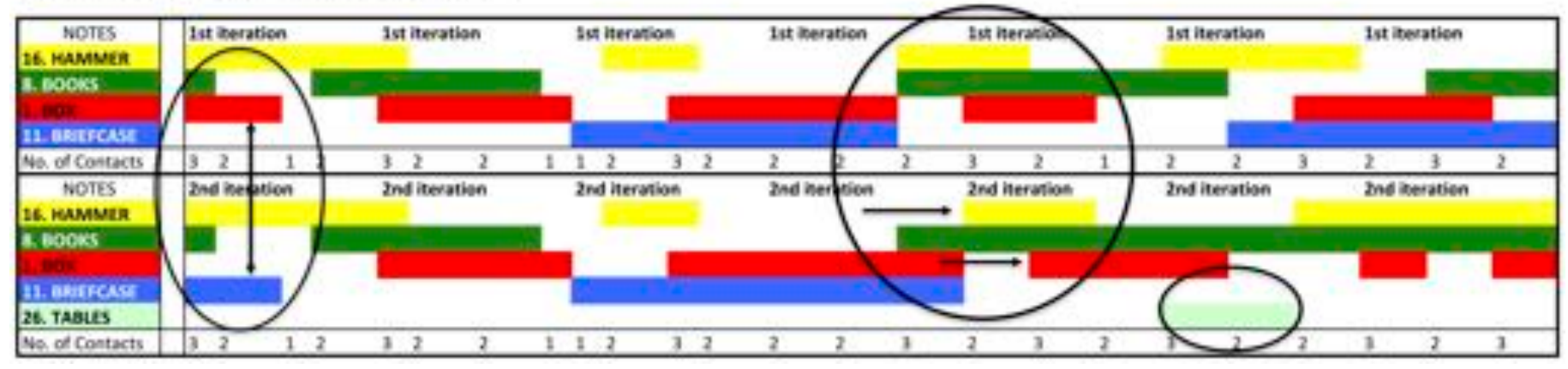


you heard them, the more different they did sound' (Riley in Potter 2002, 105). Although the performers in Schrödinger 'go through repetitive sequences of sitting and standing with clockwork precision' (Mastoris 2012) these sequences are changing: the rules are being adapted and the intentions associated with each repetition are certainly not consistent. The act of observing repetition alters that repetition, and significantly shifts the audiences' attention on to how they read, rather than what they are reading; this again identifies the structural qualities of the work as fundamental to any conceptual understanding that one might receive. Matthew Goulish, of theatre company Goat Island, explains that in repetition 'what some see as a single moment repeating, others see as a nonrepeating series of similar moments' $(2000,33)$, and it is this duality of perception that is being played with in the composition of Schrödinger. The audience view the work as something repetitive (singular) and something in process (fluid), just as the electron, as quantum physics tells us, is both particle and wave.

\section{$\underline{\text { Schrödinger }+ \text { Resulting Patterns }=\text { Awareness }}$}

Performing a work such as Schrödinger, which relies on an ability to play the composition with precision and accuracy, is comparable to minimalist practice in that it also 'sees the surrounding world as an extension of the self or the self as something programmed by outside forces' (Lasch in Fink 2005, 86). As the performers move through a system of limitation and restriction, responses invariably revolve around their place inside the score, where they are no more or less important than the other performers, objects or activities they share the space with. Thus, patterns and phrases develop from inside the structure of the piece, and the performers' interpretation of the score is established through an understanding of what effect their decisions might have on the composition as a whole. This resonates with the minimalist concept of 'ego-free musical awareness' (Fink 2005, 232) as the dissolution of the performer's control, in the act of working inside such a system, aids the 'development of a true ensemble style in which no performer draws attention to his [or her] own part at the expense of others' (Potter 2002, 112-113). Rather than making decisions based on individual tastes or intentions, the performers have to shift their thinking towards a compositional thought-process, abandoning subjective reasoning and replacing this with an objective negotiation of the external forces and entities they encounter.

Minimalism, as 'an art that enact[s] the denial of subjectivity and the collapse of goaldirected desire' (Fink 2005, 118), is also apparent in Schrödinger's score, especially for its performers. Any alteration to the established patterns can have severe consequences if not responding to the system as a whole and disrupting the flow of the work has to be avoided at all costs. The fast pace of the composition means performers and objects must be in specific places at specific times and although there is freedom in how we get from one point to another this cannot be 
at the expense of the larger score. In the making and performing of Schrödinger 'each element, be it object or movement, is included on the basis of its relationship with the whole' (Brown 2007, 5), and the score (the concrete set of rules, observations, and mathematical processes that join the materials together) is situated at the forefront of any negotiation in the moment of rehearsal or performance. Attending primarily to the patterns that emerge from the repetitive performance score, as opposed to projecting our own goals and personalities on the work, resembles the type of resulting patterns one discovers in minimalist music. The repetitive phrases become subject to a range of intricate patterns depending on which notes shift into the foreground of the work at any given moment. The interchangeable nature of these repetitions, where one note or phrase can be prioritised over another, allows the performers in Schrödinger to create a variety of melodies in each iteration of the score from what is essentially the same repetitive cycle. Comparable to Riley's 'idea of creating music directly in the act of playing' (Duckworth 1995, 268), the performers find interesting ways to play with the composition's narrow parameters and accumulate an array of interchangeable connections that they can call upon in the work. As the performers notice these resulting patterns and build upon them, they provide more layers for the audience to discover. Just as Riley's music provides 'counterpoints in textures often sufficiently dense to frustrate any attempt to untangle them' (Potter 2002, 14), the multiple associations and connections that we continually add to in Schrödinger become more complex as the patterns they create evolve over time.

\section{Conclusion}

The constraint of using only twenty-eight workable notes suggests a particularly minimalist perspective in the work of Schrödinger, and the performance certainly adheres to the principles of reduction, repetition and gradual processes inherent in musical minimalism. These compositional, musical, strategies attempt to displace the conventional meaning-making process in the development of the project and instead 'create structure, meaning and effect in ways similar to music' (Roesner in Rebstock 2012, 354). The idea that minimalism, as an aesthetic and philosophical position, can be used to understand the resistance of goal-orientated, ego-driven narratives in Schrödinger demonstrates how this musicalisation of theatre practice is embedded in the way Reckless Sleepers devise work in the rehearsal process. Many of Reckless Sleepers' projects attempt to find an appropriate organisational frame in which material can reside, and for Schrödinger this frame is one of minimalist composition. One might begin to look at a range of their work through this compositional lens; recognising that Negative Space (2015) has a structural quality similar to jazz music in how it plays with call and response or how it allows performers to improvise around an agreed set of rules; that The Last Supper (2002) might utilise the textural organisation of chamber music in how it provides a melodic conversion of the text across the three 
performers; or that The Pilots (2008) employs a compositional strategy similar to an extended pop music re-mix in how it takes recognisable elements of the Wham! classic, Club Tropicana (1983), and arranges them in surprising ways. This exposure to compositional thinking and the offer of an alternative approach to examining and assessing the function of Reckless Sleepers' performances provides further insights into the devising, rehearsing, and performing of these projects as a specific mode of compositional craft. From my own experience of working with Reckless Sleepers, it seems that this attention to the compositional details is firmly rooted in the company's approach to devising contemporary theatre. Born out of an obsession with mathematics and structures, with the organisation of material through time and space, and with a desire to not offer a fixed position in regard to meaning or conclusive singular reference points, Reckless Sleepers make projects that bring form to the foreground. These projects celebrate structure, they concentrate on the how and not the what, and if an audience might read the work through an engagement with this musicality then they may discover a wider range of possibilities in the experience being offered: finding purpose and meaning in the form of the work as well as its content. Schrödinger is a significant marker in the company's history, which highlights the continual re-assessment of those same twenty-eight notes over a twenty-year period. The project will continue to evolve and adapt as time moves forward, finding alternative routes and connections between the notes in order to increase the range of choices that can be made in the moment of presentation. I am not suggesting that Artistic Director Mole Wetherell is a minimalist, but he does favour an economical exploration of limited materials and organises these materials and objects through processes similar to music composition in general. Compositional decisions, and the use of this kind of musical discourse in the rehearsal process, is at the heart of the work he, and the company, makes.

\section{REFERENCES}

Bacon, Thomas. 2011. "Reckless Sleepers: Schrödinger" Total Theatre Review, November 3. http://totaltheatrereview.com/reviews/schrödinger

Brown, Andrew, ed. 2007. TRIAL: A study of the devising process in Reckless Sleepers' 'Schrödinger's Box'. Plymouth: University of Plymouth Press.

Davachi, Sarah C. 2012. "Looking Inward: La Monte Young, Arvo Pärt, and the Spatiotemporal Dwelling Environment of Minimalist Music.” CeReNeM Journal Nov., 3: 21-36.

Duckworth, William. 1995. Talking Music: Conversations with John Cage, Philip Glass, Laurie Anderson, and Five Generations of American Experimental Composers. New York: Da Capo Press. 
Fink, Robert. 2005. Repeating Ourselves: American Minimal Music as Cultural Practice.

California: University of California Press.

Goulish, Matthew. 2000. 39 Microlectures in proximity of performance. London: Routledge.

Harrison, Nicola. 2011. "Schrödinger (Reckless Sleepers) - West Yorkshire Playhouse.” The Public Reviews, November 24. http:/www.thepublicreviews.com/schrodinger-reckless-sleepers---westyorkshire-playhouse/

Hutera, Donald. 2011. "Schrodinger at the Arnolfini, Bristol." The Times, November 9. http://www.thetimes.co.uk/tto/arts/stage/theatre/article3221295.ece

Locke, Trevor. 2011. "Schrodinger at CURVE." Arts in Leicester, May 11.

http://www.artsinleicestershire.co.uk/theatre/theatre reviews2011.htm\#schrodinger

Mastoris, Strat. 2012. “Schrodinger's Box.” Fringe Review, October 25.

http://www.fringereview.co.uk/fringeReview/5137.html

McPhee, Rod. 2011. "Review: Schrodinger: Reckless Sleepers." Yorkshire Evening Post, December 1. http://www.yorkshireeveningpost.co.uk/lifestyle/arts-entertainment/theatre-reviews/reviewschrodinger-reckless-sleepers-1-4022975

Mertens, Wim. 1983. American Minimal Music. London: Kahn \& Averill.

Nyman, Michael. 1999. Experimental Music: Cage and Beyond. $2^{\text {nd }}$ ed. Cambridge: Cambridge University Press.

Potter, Keith. 2002. Four Musical Minimalists: La Monte Young, Terry Riley, Steve Reich, Philip Glass. Cambridge: Cambridge University Press.

Rebstock, Matthias, and David Roesner, eds. 2012. Composed Theatre: Aesthetics, Practices, Processes. Bristol: Intellect.

Riley, Terry. 1964. In C. New York: Associated Music Publishers Inc.

Sadie, Stanley, and Alison Latham, eds. 1996. The Cambridge Music Guide. Cambridge: Cambridge University Press.

Schwarz, Robert K. 1996. Minimalists. London: Phaidon Press.

Westerside, Andrew. 2011. "Reckless Sleepers: Schrödinger | The Lowry, Salford Quays | July 2011." Peer Review, Manchester. 


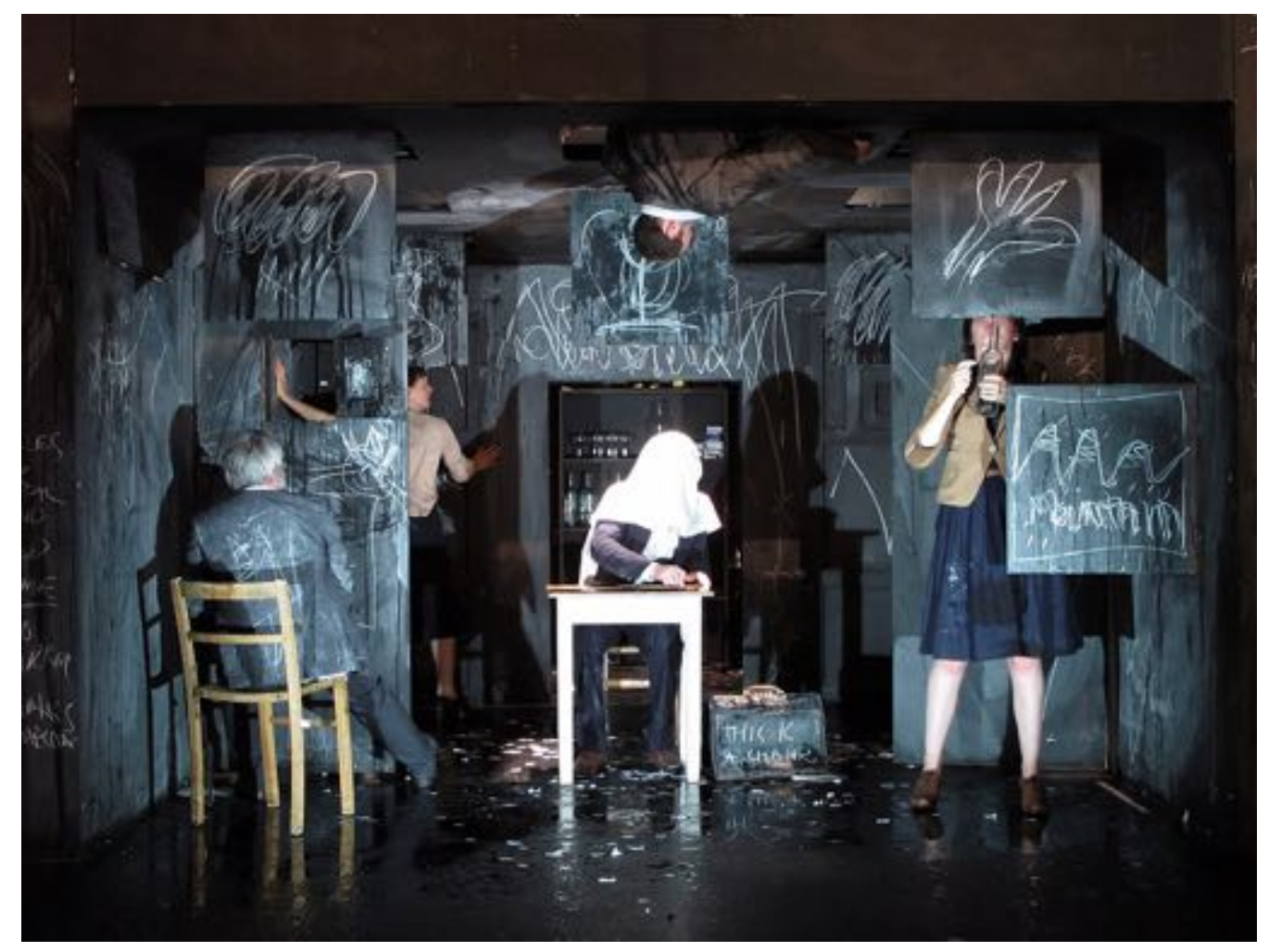




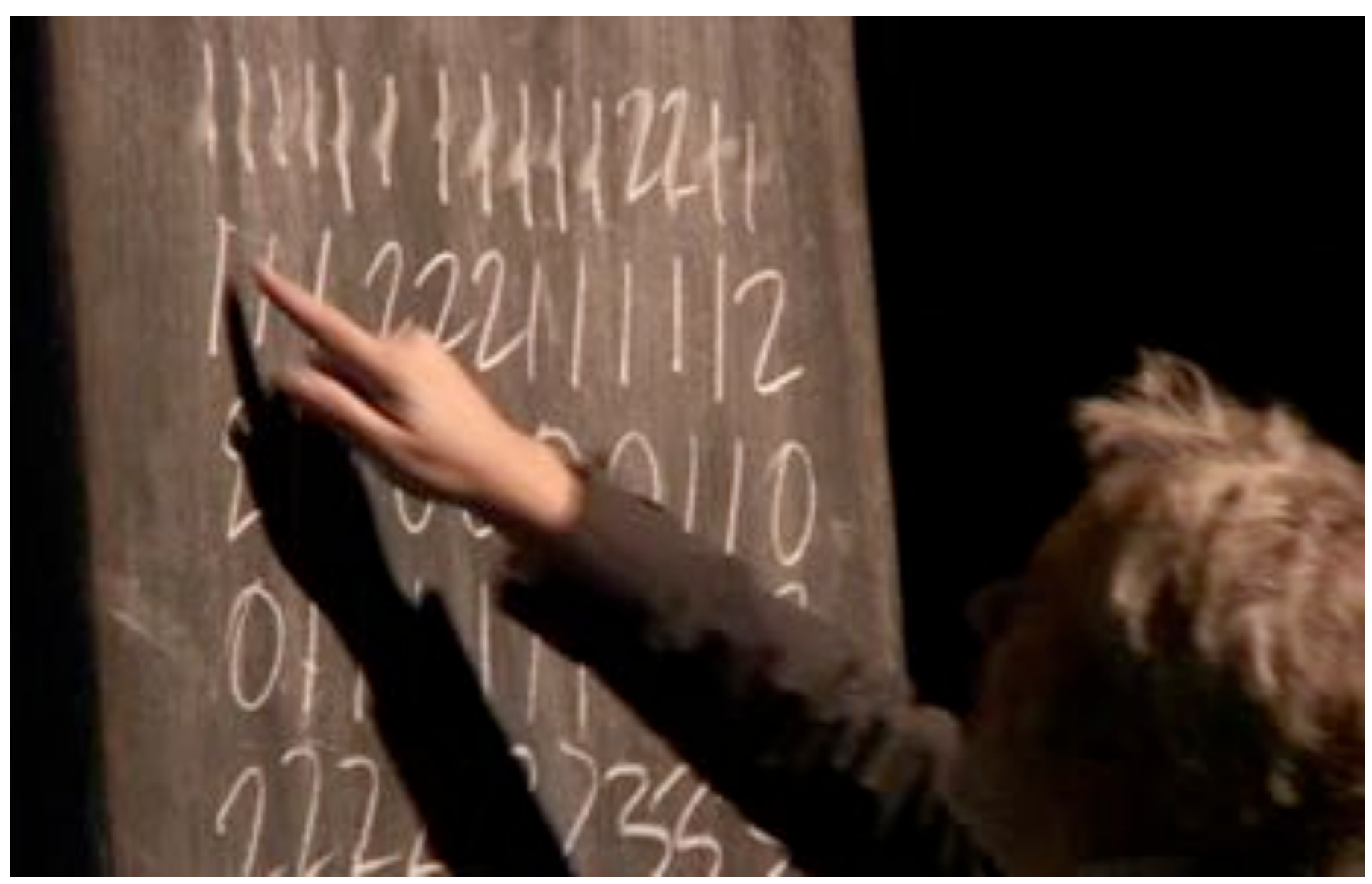




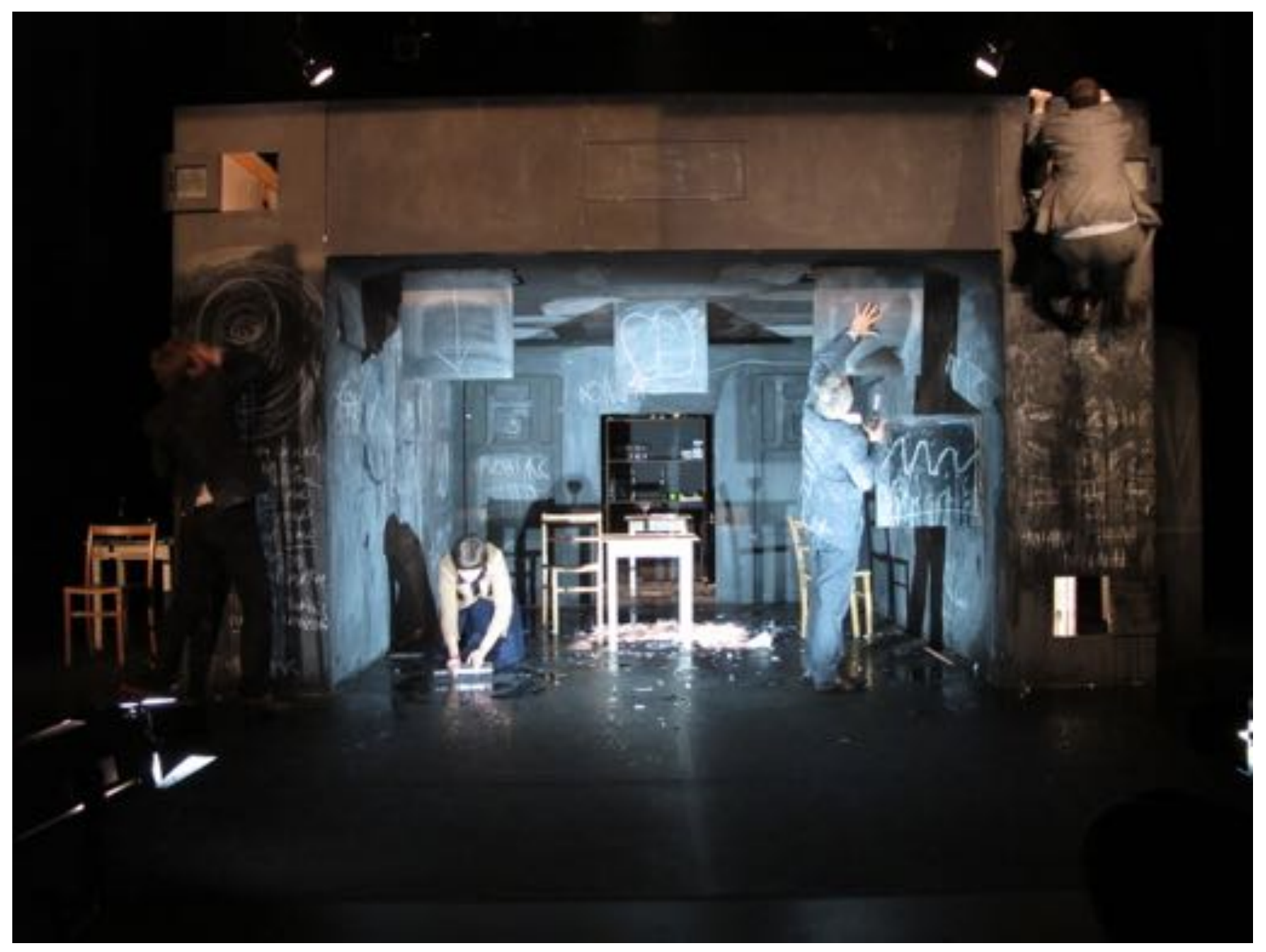




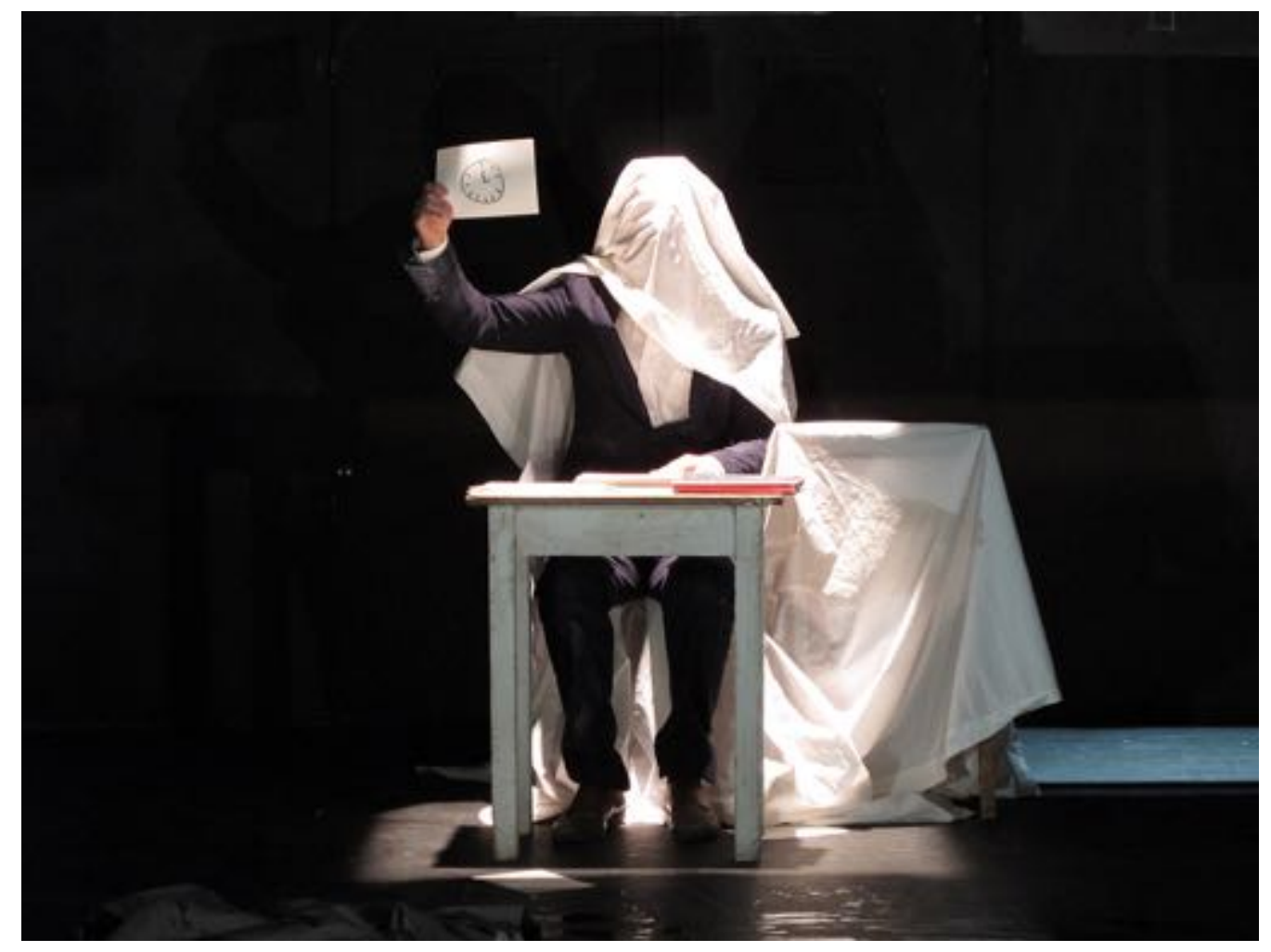




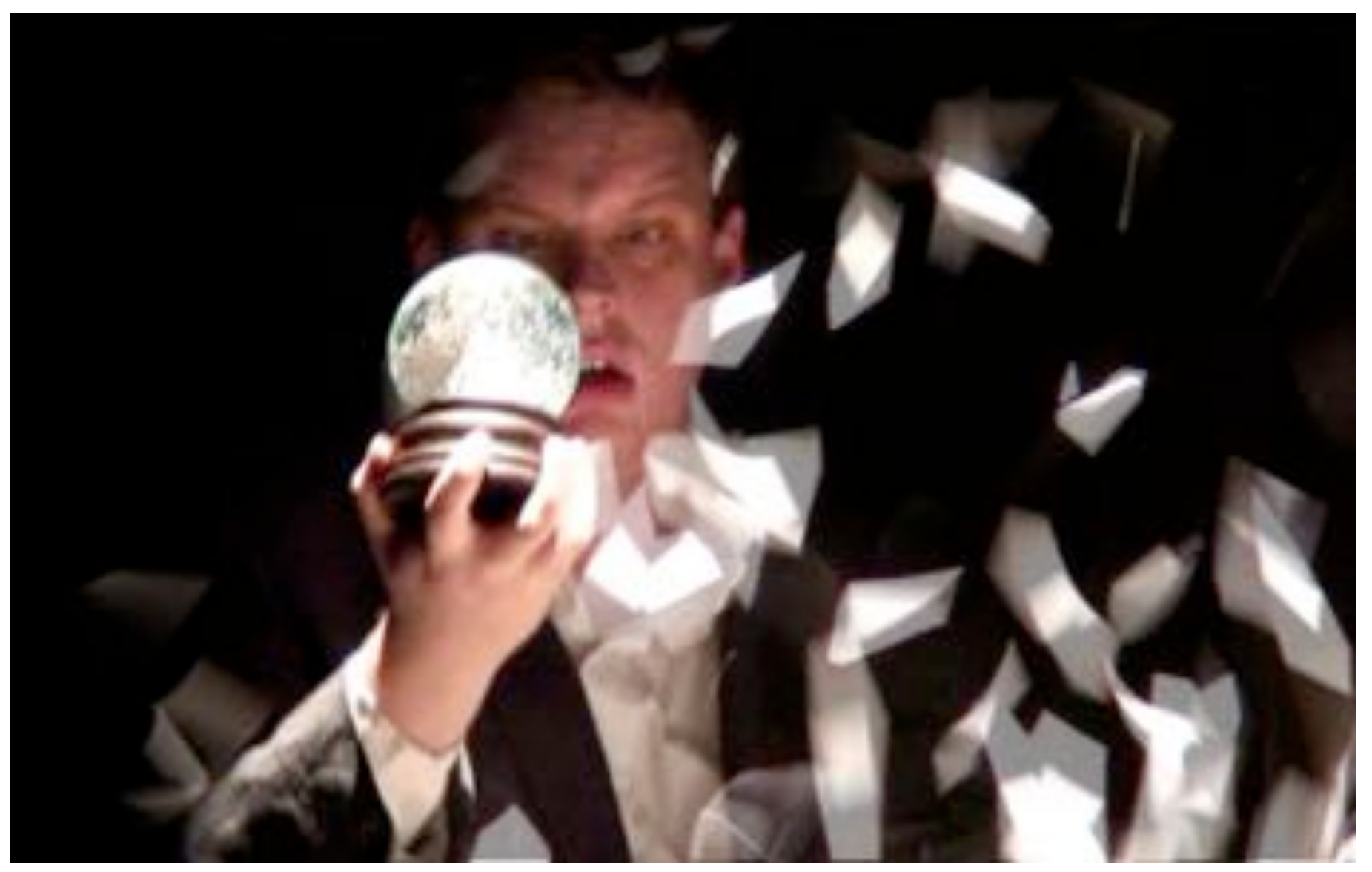




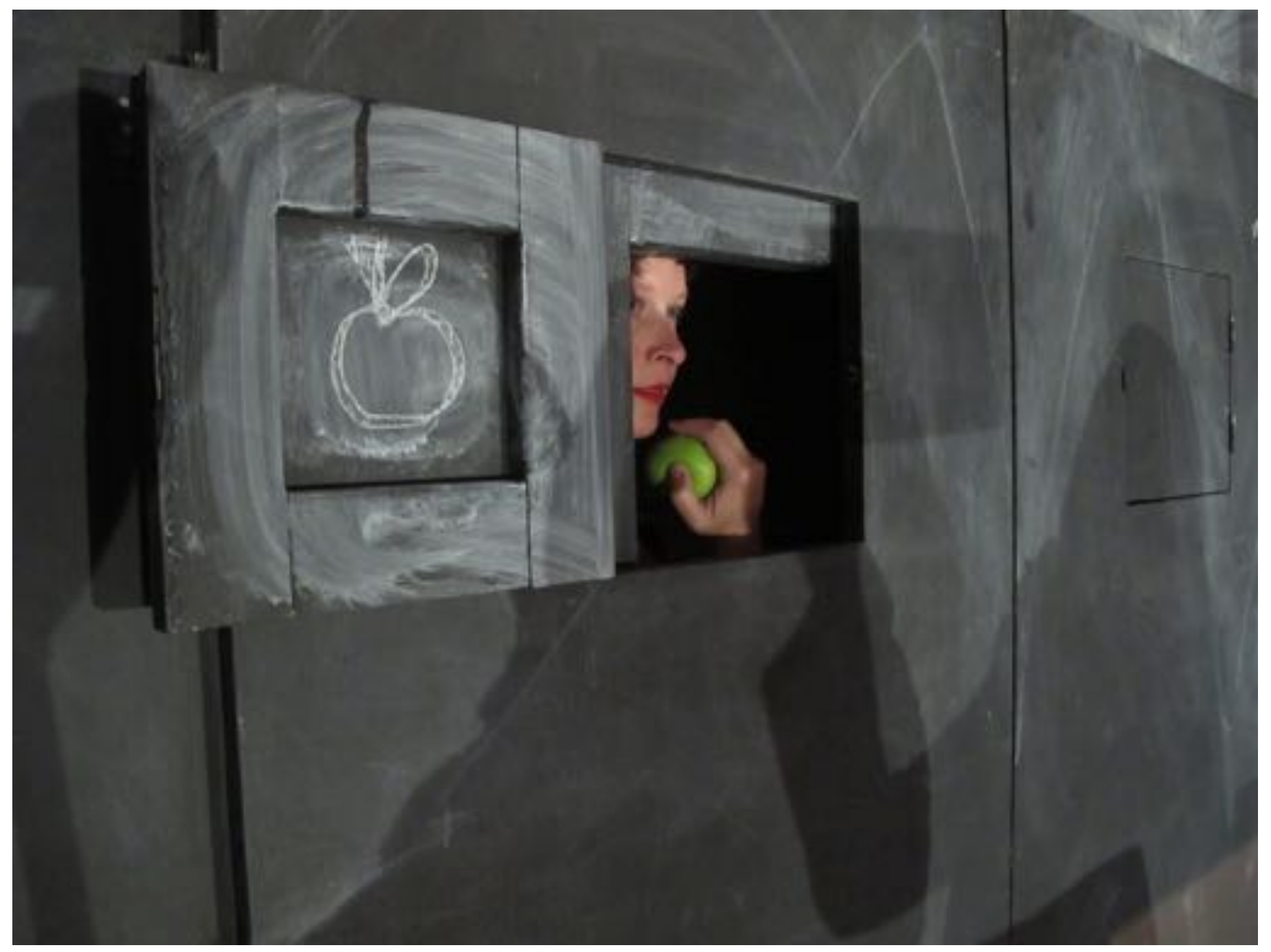




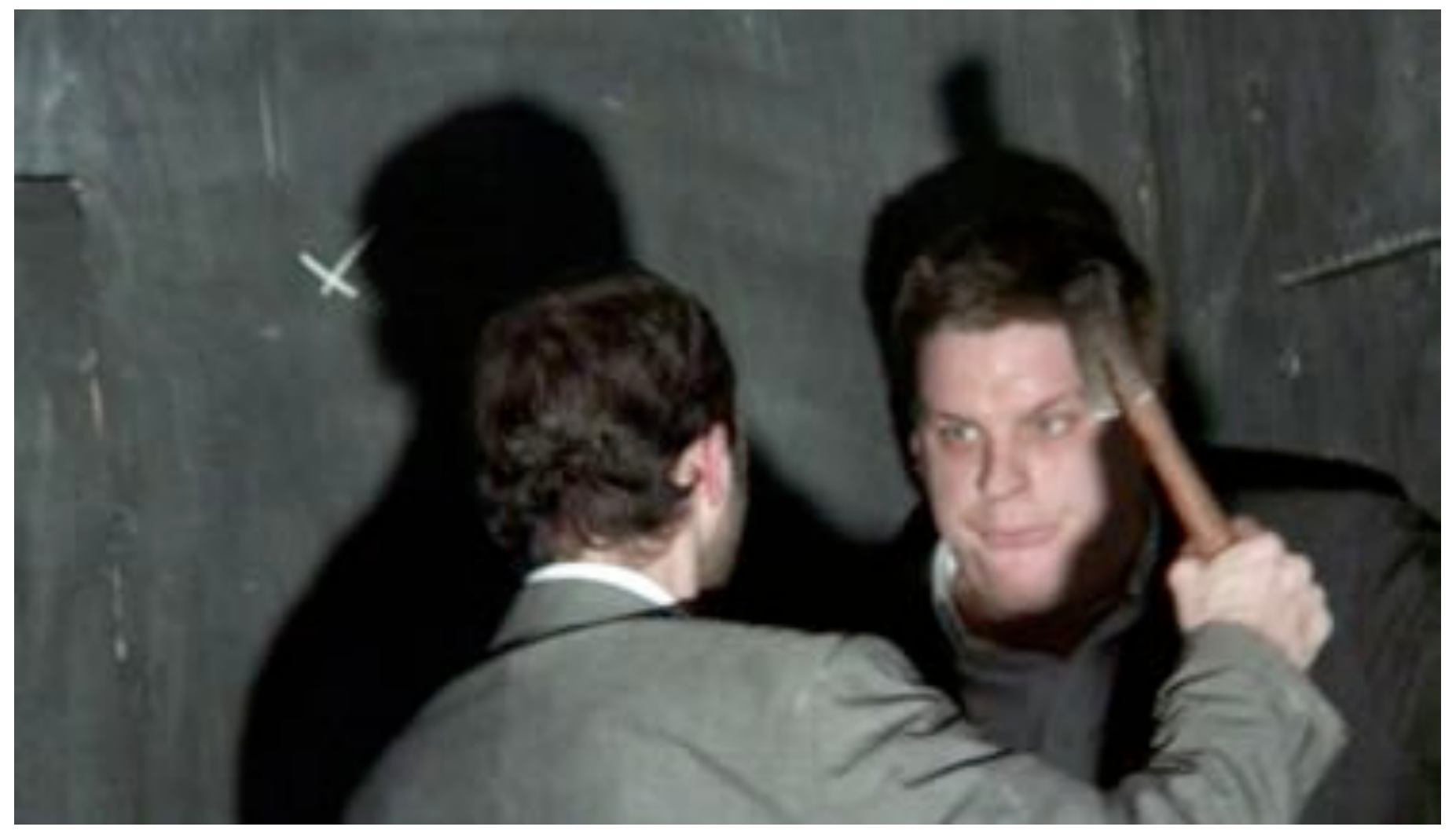




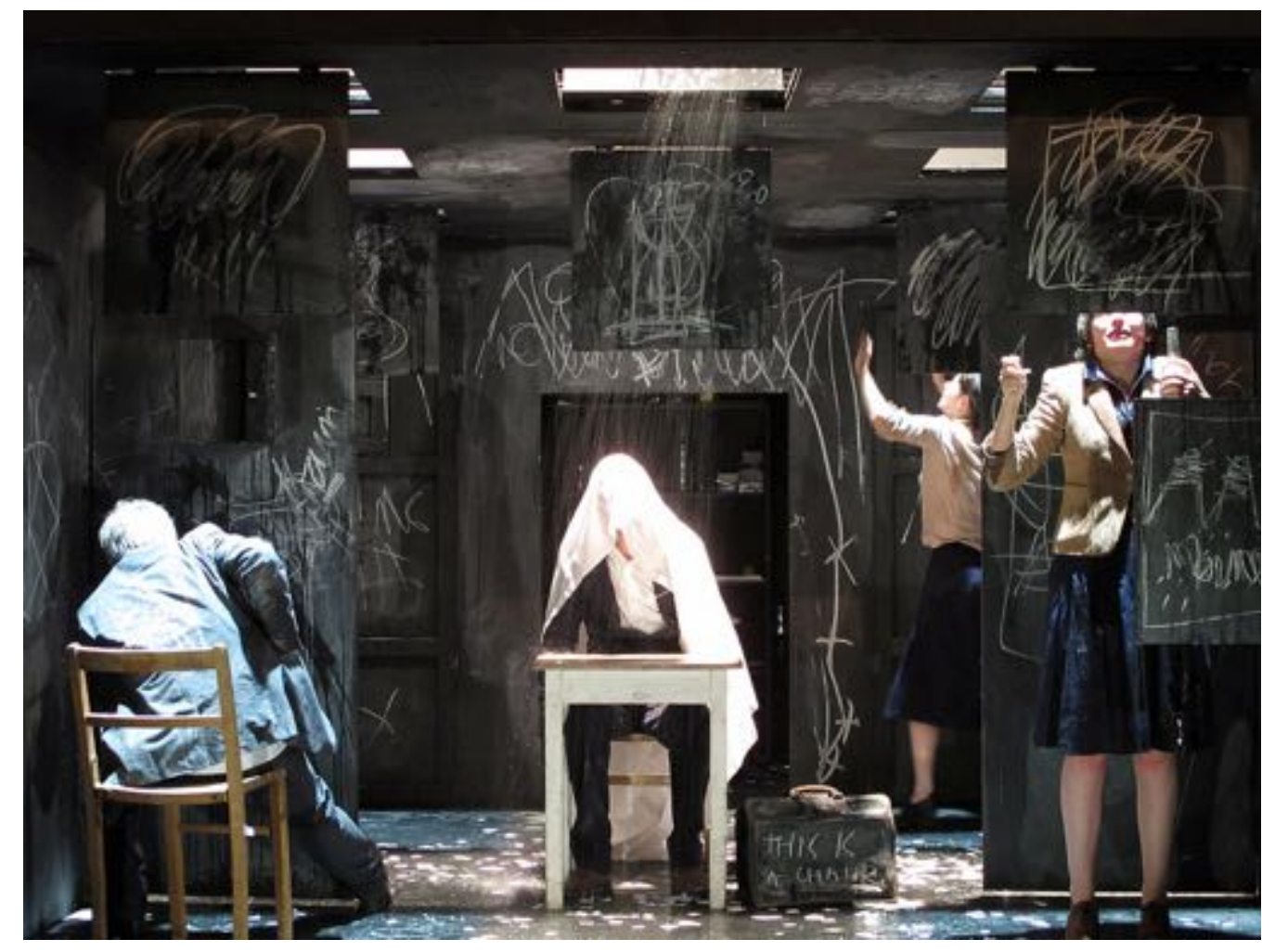




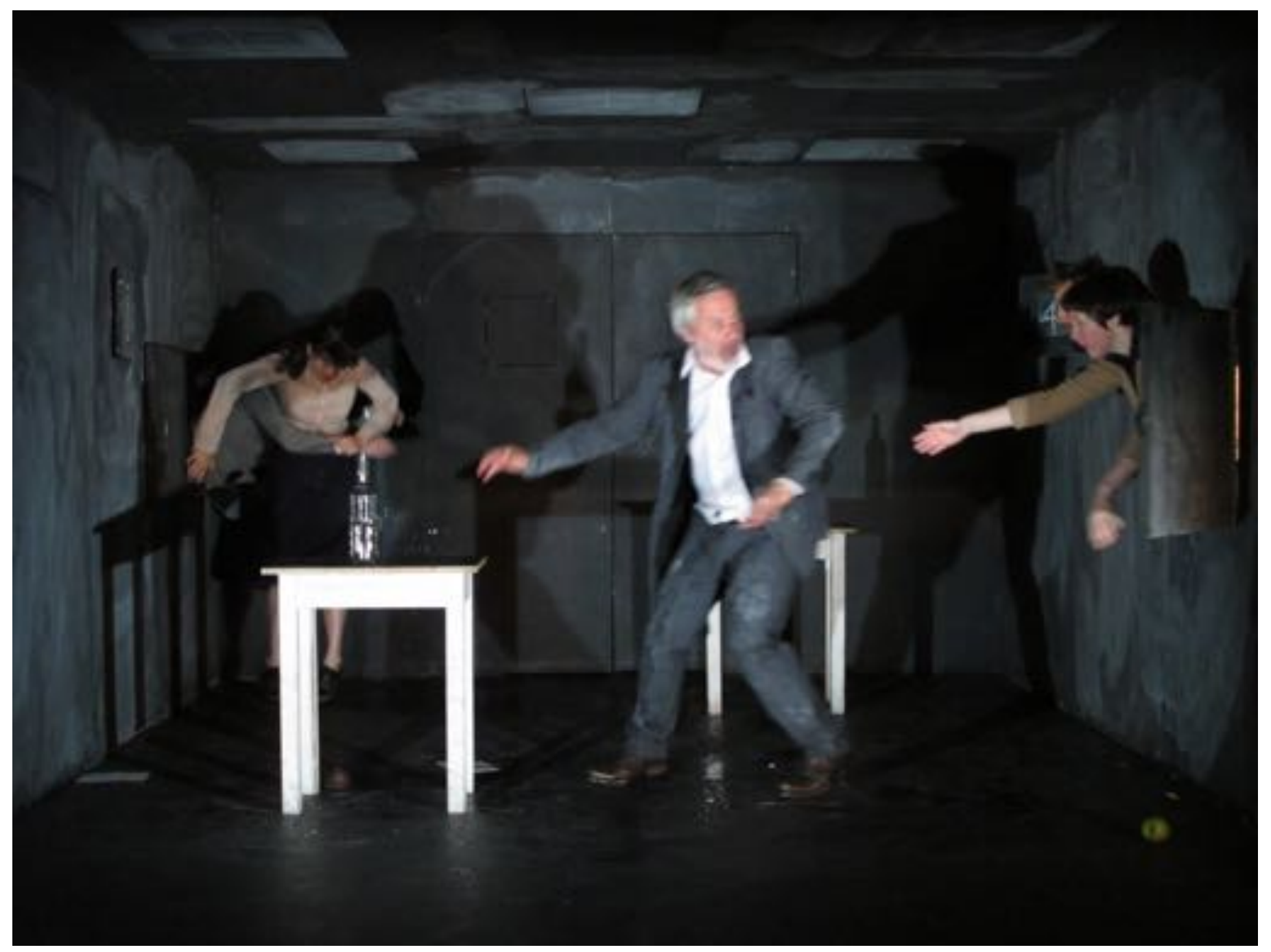

